\title{
Student Performance Shows Slight Improvement When Open Notes are Used during Information Systems Exams
}

\author{
Doris Duncan \\ California State University, East Bay, Hayward, CA, USA \\ doris.duncan@csueastbay.edu
}

\begin{abstract}
This paper summarizes findings of teaching eight sections of the same information systems college course in the same format with one major exception. Five sections had notes available for reference during the final exam whereas three sections did not. The author's primary hypothesis that students in the five sections using notes would perform significantly better than the other sections on the exam was not supported. The author also analyzed exam results for the sections allowed to use notes and found there was a significant difference in how individual students who chose to use notes performed compared to those who chose not to use notes. This topic will be of most interest to faculty who teach information systems oriented courses but may of interest to anyone who teaches or takes classes.
\end{abstract}

Keywords: IS Education, IT Education, CIS Education, Informatics Education, Exam Techniques

Full version of this paper has been fast-tracked for publication in the Journal of IT Education 